\title{
The influence of the extent of surgery on the neurological function and survival in malignant glioma. A retrospective analysis in 243 patients
}

\author{
Ch J Vecht, C J J Avezaat, W L J van Putten, W M H Eijkenboom, S Z Stefanko
}

\begin{abstract}
A retrospective analysis was performed on 66 patients with anaplastic astrocytoma (AA) and 177 patients with glioblastoma multiforme (GM). The prognostic importance of age, performance status, tumour location, extent of surgery and radiation treatment was studied. Radiation therapy gave a significant improvement in survival in both AA $(p<0.003)$ and GM $(p<0.002)$, but was given only to patients in a good neurological condition. Both younger age $(p<0.003)$, and good preoperative performance status $(p<0.002)$ were associated with a longer survival in $\mathbf{A A}$, but not in GM. Extensive surgery was correlated with a better immediate postoperative performance, a lower onemonth mortality rate and a longer survival, in both AA and GM. There was no relationship between preoperative neurological function status and the extent of surgery. Because of the retrospective nature of this study, the conclusion is that performing extensive surgery instead of limited surgery does not lead to more deterioration in postoperative neurological function.
\end{abstract}

Anaplastic astrocytoma (AA) and glioblastoma multiforme (GM) both carry a poor prognosis with a median survival time of 24 months and nine months respectively after surgery and radiotherapy. ${ }^{1-5}$ Treatment with adjuvant chemotherapy has been of additional, albeit moderate, benefit (median survival \pm 11 months in GM). ${ }^{1245}$ Recently, attention has been paid to the influence of more extensive surgery on the performance status and survival, although in rather small series. ${ }^{6-9}$ However, performing only limited surgery or no surgery is common, probably out of fear of inflicting unnecessary damage on a patient with a poor short-term prognosis. ${ }^{1011}$ It has also been our policy to perform surgery particularly for obtaining a histological diagnosis without in many cases attempting to remove a substantial amount of tumour. We analysed the outcome of this approach and examined the influence of the type of surgery and other prognostic factors on the immediate postoperative quality of life and length of survival.
Patients and methods

All the patients with a histologically verified diagnosis of a supratentorial malignant glioma in a ten year period from 1 January 1975 until 31 December 1984, were included in this study. Analysis was made for age, sex, neurological signs and symptoms, pre- and postoperative neurological function class and performance status, tumour location, type and extent of surgery, postoperative complications, radiation therapy and survival.

The performance status of the patient was scored by the neurological function classification on a four tiered scale: ${ }^{12}$

0 Able to work, neurological findings minor or absent. (includes: mild headache, epileptic insults controlled with anticonvulsants, normal mental status, slight hemiparesis, slight sensory disturbances, minimal aphasia, no sphincter disturbances, minimal hemianopia, reflex abnormalities permitted).

1 Able to be at home; nursing care not necessary; neurological findings not serious. (includes: headache, epileptic insults, normal mental status, slight aphasia possible, some apathy permitted, slight dysarthria, mild sensory disturbances, hemiparesis grade 4 (MRC scale), mild aphasia, no sphincter disturbances, hemianopia).

2 Requiring hospital admission and medical care with major neurological findings. (includes: organic brain syndrome, severe headache, nausea/vomiting, aphasia, hemiparesis grade 2-3, hemihypalgesia (-anaesthesia), (hemi-) ataxia, sphincter disturbances, wheelchair dependent)

3 Requiring hospital admission and serious physical or neurological state including coma. (includes: diminished consciousness, severe aphasia, hemiplegia (0-1), severe ataxia, bedridden more than $50 \%$ of the time).

The preoperative function class was assessed at admission before surgery, and the postoperative function class was the performance status at the time of discharge from the hospital and before radiotherapy was instituted. All charts contained a generally extensive record of the operation. From these notes the following semiquantitative estimations of the extent of tumour resection were made:

1 Stereotactic biopsy (performed since 1983). 2 Internal decompression ( < estimated $25 \%$ tumour tissue removed). This primarily addresses a craniotomy with internal decompression by suction of necrosis or fluid from 
the intratumoural cysts with one or more biopsies from the tumour wall. No serious attempt for tumour removal was made.

3 Small partial resection (estimated $25-75 \%$ tumour removal). This was scored when an attempt for removal was made; however, it was clear that a substantial amount ( $>$ estimated $25^{\circ}{ }_{0}$ ) of tumour had been left in place. 4 Large partial resection (estimated 75-95\% tumour removal). A serious attempt for removing as much tumour as possible was made, but still a certain amount ( $<$ estimated $25^{\circ}{ }_{0}$ ) could not be removed.

5 Gross total removal. This applied when a gross macroscopic tumour resection was made, or when the surgeon felt that only a minimal amount of tumour ( $<$ estimated $5 \%$ ) was left in place.

Because no routine postsurgical Computer Tomography (CT) scanning was performed, exact tumour removal from pre- and postsurgical CT comparisons could not be made.

\section{Histological diagnosis}

All histological slides were judged or reviewed by the neuropathologist (SZS), according to validated criteria in low grade astrocytoma, AA and GM. ${ }^{13-15}$ Mixed oligo/astrocytomas were excluded from the analysis. This study only refers to patients with an AA or GM of supratentorial location.

\section{Radiotherapy}

Radiotherapy was given to patients with AA with a good performance status (neurological function class 0 or 1 ).

Patients with GM as a rule did not receive radiotherapy, although 12 out of 182 patients did undergo this treatment for unspecified reasons.

Patients received radiotherapy in a midplane tumour dose in five fractions per week (2.0 Gy per day) up to $46 \mathrm{~Gy}$ via large parallel opposing lateral fields with appropriate shielding and encompassing the entire cranial contents. Thereafter, a boost was delivered to the tumour area within wide margins, up to 54-57 Gy total dose.

\section{Statistical methods}

Survival curves and mortality rates were calculated with the actuarial method of Kaplan and Meier. The Cox proportional hazard model was used to assess the impact of patient factors such as age and performance status and treatment factors such as radiotherapy and the extent of surgery on survival in a multivariate model.

\section{Results}

There were 66 patients ( 37 males, 29 females) with $\mathrm{AA}$ and 177 patients (88 males, 89 females) with GM.

Age distribution, neurological function class and extent of surgery

The mean age for AA was 49.3 years (SD $17 \cdot 2)$, which was younger than the mean age
Table 1 Age distribution

\begin{tabular}{lll}
\hline & $\begin{array}{l}\text { Anaplastic } \\
\text { astrocytoma } \\
(n=66)\end{array}$ & $\begin{array}{l}\text { Glioblastoma } \\
\text { multiforme } \\
(n=177)\end{array}$ \\
\hline Age (in years) & & \\
$\leqslant 40$ & $32^{\circ}{ }^{\circ}$ & $7 \%$ \\
$>40-\leqslant 60$ & $38^{\circ}{ }^{\circ}$ & $50 \%$ \\
$>60$ & $30^{\circ}{ }_{\circ}$ & $43 \%$ \\
\hline
\end{tabular}

for GM: $57 \cdot 1$ years (SD 10·7). The age distribution in table 1 shows that patients especially in the younger age group of less than 40 years are rarely present among the GM patients.

For preoperative neurological function there was no evidence of a gross difference between the two histological groups (table 2), but there was a weak association between age and preoperative neurological function: patients with a poor neurological function class were on average older than patients with a good function class ( $p<0.05$, see table 3 ).

The majority of the patients had limited surgery, that is, an internal decompression $(57 \%)$ or a small partial resection $(24 \%)$. There was no evidence of an association between the extent of surgery and age or preoperative neurological function class (table 4), which may be partly due to the fact that the number of patients with extensive surgery (that is, a large resection or a gross total removal) was small $(\mathbf{n}=30)$.

Table 5 compares the postoperative and the preoperative neurological function class. The majority of the patients were unchanged $(51 \%), 29 \%$ showed an improvement and $19^{\circ}$ o showed a deterioration. Table 6 shows the relationship between the extent of surgery and the change in the neurological function class. It shows that large resections or gross total removal did not lead to more deterioration than limited surgery. In fact, it shows that with extensive surgery there was often more improvement and frequently less deterioration.

\section{Tumour location}

The associations between tumour location, pre-and postoperative function and extent of surgery were analysed by means of crosstabulations. An association was found only between tumour location and extent of sur-

Table 2 Preoperative neurological function class distribution

\begin{tabular}{|c|c|c|}
\hline $\begin{array}{l}\text { Neurological } \\
\text { function class }\end{array}$ & $\begin{array}{l}\text { Anaplastic } \\
\text { astrocytoma } \\
(n=66)\end{array}$ & $\begin{array}{l}\text { Glioblastoma } \\
\text { multiforme } \\
(n=177)\end{array}$ \\
\hline $\begin{array}{l}0 \\
1 \\
2 \\
3\end{array}$ & $\begin{array}{l}8^{\circ}{ }^{\circ} \\
32^{\circ} \circ \\
38^{\circ}{ }^{\circ} \circ \\
22^{\circ}{ }_{0}\end{array}$ & $\begin{array}{r}7^{\circ} \circ \\
21^{\circ}{ }^{\circ} \\
44^{\circ}{ }^{\circ} \\
28^{\circ}{ }_{0}^{\circ}\end{array}$ \\
\hline
\end{tabular}

Table 3 Age in relation to neurological function

\begin{tabular}{lcl}
\hline Neurological function class & No of patients & Mean age \\
\hline 0 & 17 & $52 \cdot 1$ \\
1 & 57 & $51 \cdot 0$ \\
2 & 105 & $56 \cdot 0$ \\
3 & 63 & $58 \cdot 1$ \\
\hline
\end{tabular}


Table 4 Extent of surgery in relation to preoperative neurological function class

\begin{tabular}{llllll}
\hline $\begin{array}{l}\text { Preoperative } \\
\text { neurological } \\
\text { function class }\end{array}$ & $\begin{array}{l}\text { Stereotactic } \\
\text { biopsy }\left({ }^{\circ}{ }_{0}\right)\end{array}$ & $\begin{array}{l}\text { Internal } \\
\text { decompression (\%) }\end{array}$ & $\begin{array}{l}\text { Small } \\
\text { resection (\%) }\end{array}$ & $\begin{array}{l}\text { Large } \\
\text { resection }(\%)\end{array}$ & $\begin{array}{l}\text { Gross } \\
\text { removal (\%) }\end{array}$ \\
\hline $0 \quad(\mathrm{n}=17)$ & 6 & 65 & 12 & 0 & 18 \\
$1 \quad(\mathrm{n}=57)$ & 7 & 53 & 25 & 7 & 9 \\
$2(\mathrm{n}=105)$ & 10 & 59 & 20 & 8 & 4 \\
$3(\mathrm{n}=63)$ & 2 & 57 & 32 & 5 & 5 \\
\hline
\end{tabular}

Table 5 Numbers of patients $\left({ }^{o}{ }_{o}\right)$ with a change in neurological function class before and after surgery $\left(n=243^{\star}\right)$

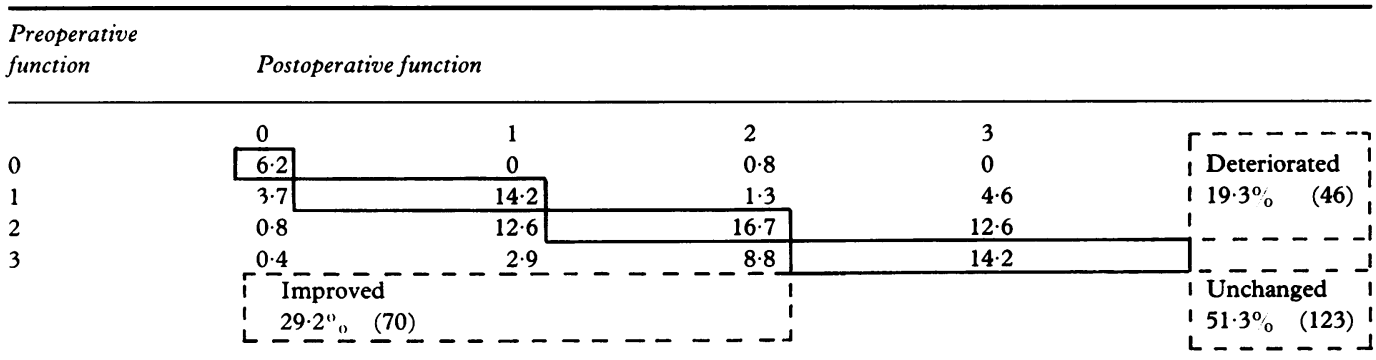

*In four of the 243 patients insufficient data for analysis were recorded.

gery: occipital and deep-seated locations were predominantly related with stereotactic biopsies, and parietal location with less extensive surgery $(\mathrm{p}<0.04)$.

Complications and one month mortality

The complication rate was $23.9^{\circ}{ }_{0}$ in the AA and $19 \cdot 1^{\circ}$ in the GM group. Brain oedema occurred in 23 patients, intracranial haematoma in 12 , bronchopneumonia in five, meningitis or abscess in two, systemic infection in four and thrombophlebitis in two patients. The frequency or type of complications was similar in both groups. The one month mortality rate was $20 \cdot 9{ }^{\circ}$ in $\mathrm{AA}$, and $22.5 \%$ in GM. Table 7 shows that none of the patients with a gross removal had complications, but there is no apparent trend between the complication rate and the extent of surgery. Conversely, both the one and three month mortality rates were strongly correlated with the extent of surgery: the larger the resection, the smaller the mortality rate.

\section{Survival}

Figure 1 shows that the median survival in $\mathrm{AA}$ and GM was respectively eight and four months, with a two year survival of $13 \%$ and $0.5^{\circ}{ }_{0}$ respectively. Figure 2 demonstrates the influence of age on the survival in AA in the $<40,40-60$, and $>60$ years of age groups. Age is significantly $(\mathrm{p}<0.002)$ related to prognosis in AA. There was no relationship between age

Table 6 Change in pre-and postoperative neurological function in relation to extent of surgery

$\left.\begin{array}{lllc}\hline & \begin{array}{l}\text { Improved } \\ (\%)\end{array} & \begin{array}{l}\text { Unchanged } \\ (\%)\end{array} & \begin{array}{c}\text { Deteriorated } \\ (\%)\end{array} \\ \hline \text { Stereotactic biopsy }(\mathrm{n}=16) & 19 & 75 & 5 \\ \text { Internal decompression }(\mathrm{n}=136) & 21 & 52 & 26 \\ \text { Small resection }(\mathrm{n}=56) & 45 & 43 & 13 \\ \text { Large resection }(\mathrm{n}=15) & 27 \\ \text { Gross removal }(\mathrm{n}=15) & 60\end{array}\right\} 43 \quad \begin{aligned} & 60 \\ & \end{aligned}$

^Improved or deteriorated denotes patients who showed one grade of improvement or deterioration in postoperative neurological function class. and survival in the GM group. Preoperative neurological function status was significantly $(\mathrm{p}<0.001$ ) related to survival (fig 3 ) in the AA patients, but not in GM (these curves are not shown). Figures 4 and 5 compare the survival of the patients with extensive surgery and the patients with limited surgery in AA and GM.

Only six AA patients were treated with extensive surgery. They show a better survival (generalised Wilcoxon test, $\mathrm{p}=0.08$ ). In the GM group 24 patients were treated with extensive surgery. Their median survival is four months. For patients treated with limited surgery it is three months. Although the difference between both curves is relatively small, it is statistically significant (generalised Wilcoxon test, $p=0.01)$. Figure 6 shows a clear difference in survival between non-irradiated and irradiated AA patients with a median survival of respectively three and 12 months. In the GM group the irradiated patients also show a longer survival (median nine months) than the nonirradiated patients (median three months) (fig 7).

Generally, patients with AA had radiotherapy, unless neurological function status made radiotherapy not worthwhile. Thus the division of patients who had radiotherapy or not, was highly biased, and the difference in fig 6 in three month survival between the patients with and without radiotherapy reflects this too. In general, patients with GM did not have radiotherapy. Only twelve patients had radiotherapy in this group for unstated reasons. Table 8 shows the results of the Cox regression analysis. In this multivariate model the effects of age and neurological function class were estimated separately in the AA and the GM group. In the AA group both these factors were significantly associated with the relative death rate, but this was not so for the GM group. Separate estimators for the effect of radiotherapy and the extent of surgery in the AA and GM group were not computed as the number of patients with radiotherapy in the GM group was too small as was the number of patients 
Table 7 Complication rate and one-and three-month mortality in relation to extent of surgery

\begin{tabular}{|c|c|c|c|c|}
\hline Extent of surgery & No of patients & Complications $\%$ & $\begin{array}{l}\text { One-month } \\
\text { mortality } \%,(S D)\end{array}$ & $\begin{array}{l}\text { Three-month } \\
\text { mortality } \% \text {, (SD) }\end{array}$ \\
\hline $\begin{array}{l}\text { Stereotactic biopsy } \\
\text { Internal decompression } \\
\text { Small resection } \\
\text { Large resection } \\
\text { Gross removal }\end{array}$ & $\begin{array}{r}17 \\
139 \\
57 \\
15 \\
15\end{array}$ & $\begin{array}{r}12 \\
26 \\
12 \\
27 \\
0\end{array}$ & $\begin{array}{rr}35 & (12) \\
27 & (4) \\
11 & (4) \\
7 & (6) \\
0 & -\end{array}$ & $\begin{array}{lr}59 & (12) \\
51 & (4) \\
42 & (7) \\
27 & (11) \\
13 & (9)\end{array}$ \\
\hline
\end{tabular}

with extensive resection. So the estimated relative death rates for the treatment factor radiotherapy and extent of surgery are to be considered as an average for the AA and GM group together. Both radiotherapy and more extensive surgery were correlated with a significantly longer survival. Again we emphasise that radiotherapy was given to a selected group of patients.

\section{Discussion}

Patients with a malignant glioma have a poor prognosis despite vigorous treatment with surgery, radiotherapy or adjuvant chemotherapy. ${ }^{1-5}$ For that reason, the present treatment regime is essentially palliative. A good quality of life is therefore one of the main goals of treatment in GM. Although retrospective and prospective studies, albeit performed in relatively small numbers of patients, indicate that more complete resections of malignant glioma give a better postoperative performance status and a longer survival, ${ }^{7-9} 1617$ many physicians do not refer their patients for further treatment after a CT scan has shown the high probability of a malignant glioma. ${ }^{11}$ This may stem from the fear of damaging the patient given the short expected survival. ${ }^{11}$ The relatively long period of time necessary for surgery, including the postoperative timeperiod spent in the hospital and the period of approximately six weeks for radiotherapy might be arguments for not giving further treatment. ${ }^{18}$ These reasons have led us to a modest approach in treating malignant glioma in our clinic. Surgery is mainly performed for verification of the CT diagnosis. ${ }^{19}$ In the majority of patients, surgery is limited to an internal decompression or small resection to limit further trauma to the patient.

It is important to realise that treatment choices in this study were not randomised. For that reason, although we tried to identify the motives for treatment choices, the possibility remains that other factors beyond our capacity for analysis influenced the outcome, including the chance that a more radical treatment was

Table 8 Multivariate analysis of prognostic and treatment-related factors

\begin{tabular}{|c|c|c|c|c|}
\hline & & $\begin{array}{l}\text { Relative } \\
\text { death rate }\end{array}$ & $\begin{array}{l}95 \% \text { confidence } \\
\text { limits }\end{array}$ & p-value \\
\hline $\mathrm{Age}^{\star}$ & $\begin{array}{l}\mathrm{AA} \\
\mathrm{GM}\end{array}$ & $\begin{array}{l}1.28 \\
0.94\end{array}$ & $\begin{array}{l}(1 \cdot 08-1 \cdot 53) \\
(0 \cdot 81-1 \cdot 10)\end{array}$ & $\begin{array}{l}0.003 \\
0.44\end{array}$ \\
\hline $\begin{array}{l}\text { Neurological } \\
\text { Function class }(0,1,2,3) \\
\text { Radiotherapy (yes versus no) } \\
\text { Extent of surgery }\end{array}$ & $\begin{array}{l}\text { AA } \\
\text { GM }\end{array}$ & $\begin{array}{l}1 \cdot 63 \\
1 \cdot 12 \\
0 \cdot 40 \\
0 \cdot 77\end{array}$ & $\begin{array}{l}(1 \cdot 18-2.25) \\
(0.94-1.33) \\
(\because .26-0.61) \\
(0.67-0.89)\end{array}$ & $\begin{array}{l}0 \cdot 002 \\
0 \cdot 20 \\
0 \cdot 0001 \\
0 \cdot 001\end{array}$ \\
\hline
\end{tabular}

\#The age factor was expressed in decades in this analysis. Thus the relative rate of 1.28 in the AA group means that, on average, an increase in age of 10 years goes together with an increase of the death rate by a factor of $1 \cdot 28$. chosen for patients who would have had a better prognosis anyway. Because the subgroups comprised a relatively small number of patients, the discriminative power of the analysis is limited. The retrospective character of the study also implies some imprecision of the scored data. Thus our results need to be interpreted with caution.

The epidemiological characteristics of our patient population agrees with other studies. The age and sex distribution in AA and GM is similar. ${ }^{1-5}$ The percentage of patients with AA $\left(27 \cdot 0^{\circ}{ }_{0}\right)$ is within the range of other prospective studies. ${ }^{1-5}$

\section{Postoperative performance status}

Limited surgery does not result in less deterioration in postoperative neurological function compared to extensive surgery. Patients with an internal decompression showed a postoperative deterioration in neurological function class in $26^{\circ}{ }_{0}$, in contrast to $13 \%$ and $0 \%$ in, respectively, a large partial resection and gross total removal (table 6). Although one might expect that patients with a poor preoperative neurological function would have more restricted surgery, such a relationship could not be found. Considering our results, one should realise that the majority of the patients (table 5) have a relatively poor preoperative neurological condition. This implies that under these circumstances the grading scale is more sensitive for detecting an improvement rather than deterioration. We do not believe, however, that this would influence the conclusions, as the sensitivity of the grading scale bears no relationship to the mode of treatment or any of the other prognostic factors.

There was no correlation between age and extent of surgery nor between histological

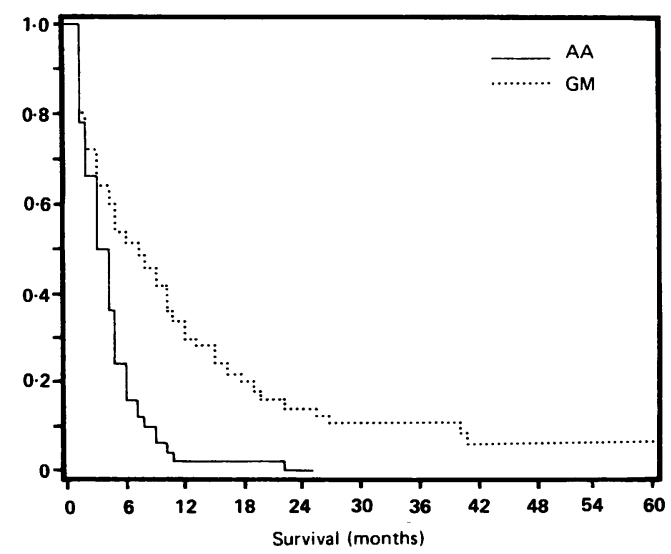

Figure 1 Survival curves in patients with anaplastic astrocytoma ( $A A$ ) and glioblastoma multiforme (GM). 
Figure 2 Survival curves of age, 40-60 years and $>60$ years. in $A A$ patients $<40$ years

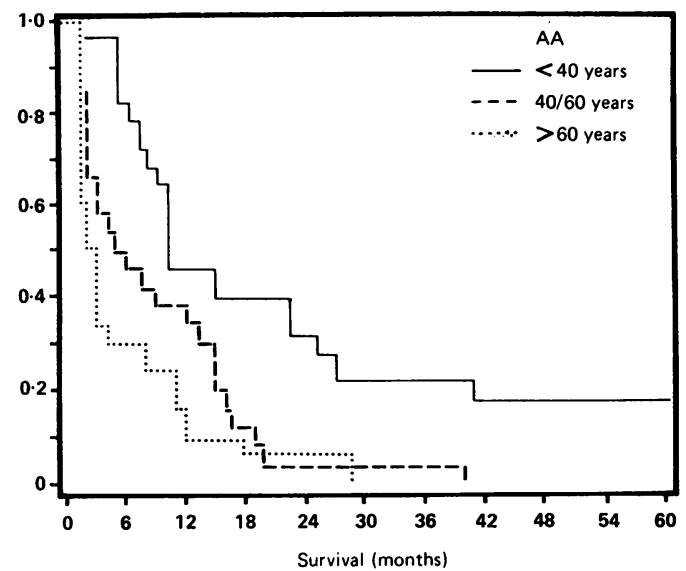

diagnosis (AA or GM) and neurological function. Tumour location did not correlate with extent of surgery, except for occipital, parietal and deep-seated locations which correlated with less extensive surgery. The same trend of less deterioration in neurological function is apparent in other studies favouring more extensive surgery when tumour location allows. ${ }^{7-9161720}$ Also the complication rate in patients with limited surgery was not less than in patients with a more extensive surgery (table 7). A striking correlation was present in one and three month mortality and extent of surgery, favouring a large or gross total resection (table 7). The high one month mortality in patients who had an internal decompression or small partial resection is similar to other studies in which limited surgery was performed. ${ }^{162122}$ Another explanation stems probably from our policy of restrained supportive care in patients with a verified diagnosis of malignant glioma and poor neurological condition. Nevertheless, a median duration of three months as found in this study is similar to other prospective series in which patients treated with surgery only were analysed. ${ }^{13}$

\section{Prognostic factors for survival}

The most important prognostic factor is the histological diagnosis showing strikingly different survival curves for AA and GM (fig 1). This underlines once more the notion that the histological criteria used here have a strong prognostic value. ${ }^{13-15}$ Because many of the analysed factors are probably interrelated to some extent, a multiple regression analysis best reflects the relative weight of the various prog-

Figure 3 Survival curves in $A A$ patients with a preoperative neurological function class 0 or 1 , or 2 or 3.

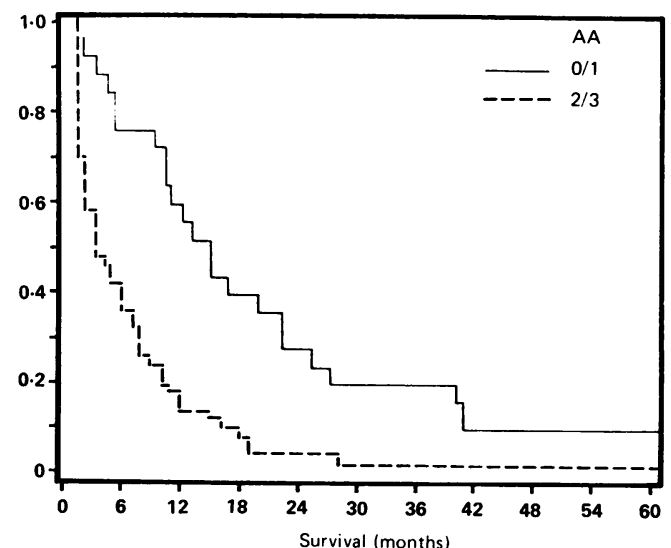

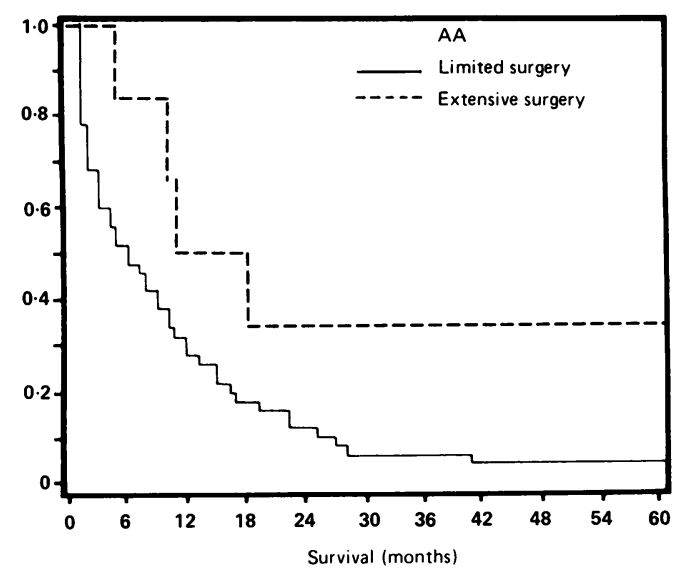

Figure 4 Survival curves in AA patients with limited surgery (small partial resection or less) or more extensive surgery (large partial or gross resection) ; $p=0.075$; generalised Wilcoxon test.

nostic factors. With this method radiotherapy emerges as a factor strongly related to survival. It should be noted, however, that an important preselection for radiotherapy was present in AA, that is, only being offered to patients in a good postoperative performance state.

The relative death rate of the patients with radiotherapy compared with the group without radiotherapy was 0.40 , corrected for the influence of performance status, age, histology and extent of surgery. This means that on average during follow up the risk of dying per unit of time for patients treated with radiotherapy was 0.40 times the same risk for patients with the same characteristics but without radiotherapy. This 0.40 may be partly due to the effect of the radiotherapy and partly to the selection of the patients. Although extensive surgery was performed in only a minority of patients, it proved to be of significant importance as a prognostic factor $(p<0.001)$. The relative death rate of the patients undergoing more extensive surgery was $\mathbf{0} \cdot 77$, compared to patients undergoing less extensive surgery. Results from other series confirm the influence of the type of surgery on survival. ${ }^{716} 17$

Both age and preoperative performance were

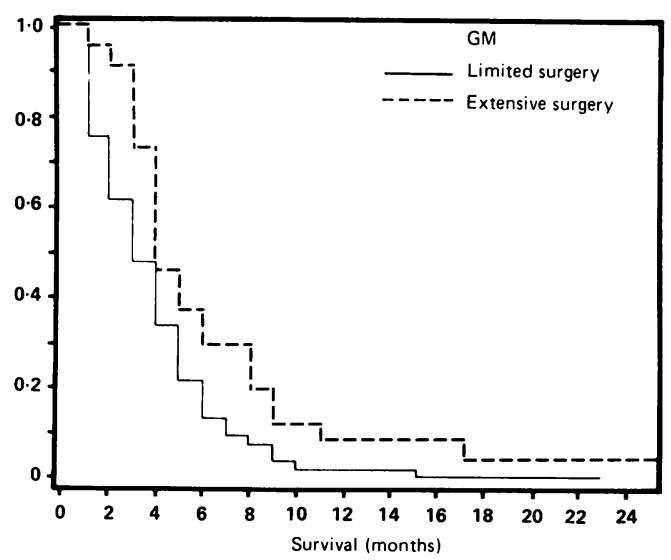

Figure 5 Survival curves in GM patients with limited surgery (small partial resection or less) or more extensive surgery (large partial or gross resection; $p=0.0115$; generalised Wilcoxon test. 
Figure 6 Survival curves in $A$ A patients with or without radiotherapy.

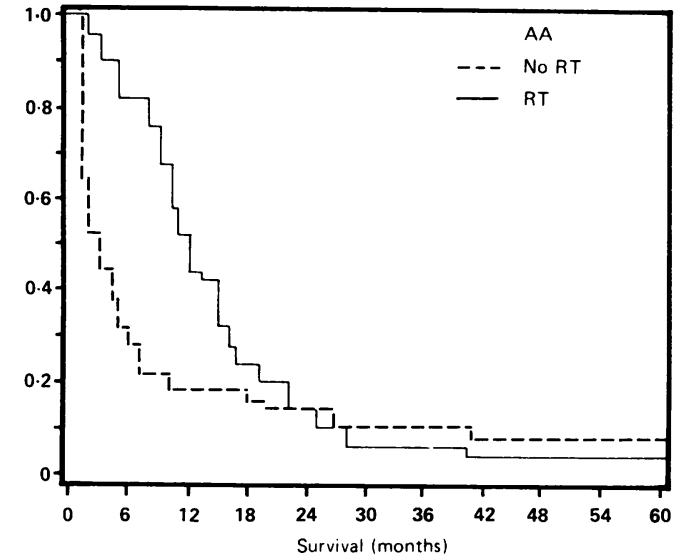

confirmed to be important prognostic factors in AA. ${ }^{1245}$ Limited surgery without radiotherapy in GM might be the explanation for the absence of an influence of age and performance status on survival, which is in contrast to what has been found in others' reports. ${ }^{124}$ Possibly, because of the short doubling-time of 15-21 days of malignant cells in GM, both age and performance status are not able to exercise their impact on prognosis. ${ }^{23}$ The extent of tumour removal is most accurately measured by comparing the pre- and postoperative CT scan. ${ }^{7-9}$ This method is preferred above the estimation by the surgeon during the operation as used here. Nevertheless, in other studies in which this latter method was used, ${ }^{116172021}$ similar differences for postoperative neurological function and duration of survival between patients with small or large resections have been found as in studies using the CT scan.

Our analysis reveals that extensive surgery is correlated with a better postoperative neurological function and a longer survival time compared to limited surgery. We cannot rule out a selection bias for extensive surgery in our population, although we were not able to detect it for preoperative neurological function and tumour location, with the exception of deep-seated, occipital and parietal location. Because of the retrospective nature of our study our conclusion can only be that extensive surgery does not lead to more postoperative neurological damage than limited surgery. Nevertheless, we believe this to be an important conclusion because surgery is often withheld or limited to a stereotactic biopsy or a small resection for fear of damaging the patient's condition. ${ }^{1011}$ Recently, in a prospec-

Figure 7 Survival curves in GM patients with or without radiotherapy.

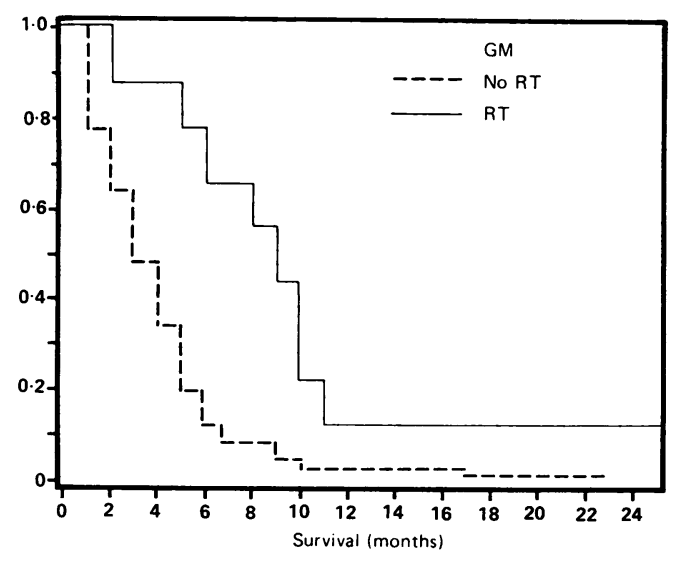

tive study it has been confirmed that extensive surgery does not lead to greater deterioration of neurological function with an equal chance of less than $20 \%$ for both limited and extensive surgery. ${ }^{9}$ Larger resections are also correlated with a longer survival as shown in retrospective and prospective studies. ${ }^{1716172224}$ Our study confirms this.

We thank Mrs M van Dishoeck and Ir C J Jongkind for their help in processing the data and Ms M Drinkwaard for secretarial help in process
assistance.

1 Walker MD, Alexander E, Hunt WE, et al. Evaluation of $\mathrm{BCNU}$ and/or radiotherapy in the treatment of anaplastic gliomas. A cooperative trial. J Neurosurg 1978;49:333-43.

2 Walker MD, Green SB, Byar DP, et al. Randomised comparisons of radiotherapy and nitrosureas for the treatment of malignant glioma after surgery. New Engl Med 1980;303:1323-9.

3 Kristiansen K, Hagen S, Kollevold T. Combined modality therapy of operated astrocytomas grade 3 and 4: A prospective multi-center trial of the Scandinavian Glioblastoma Study Group. Cancer 1981;47:649-52.

4 Chang CH, Horton J, Schoenfeld D, et al. Comparison of postoperative radiotherapy and combined postoperative radiotherapy and chemotherapy in the multidisciplinary management of malignant gliomas. A Joint Radiation Therapy Oncology Group and Eastern Cooperative Oncology Group study. Cancer 1983;53:999-1007.

5 Green BS, Byar DP, Walker MD, et al. Comparisons of carmustine, procarbazine and high-dose methylprednisolone as additions to surgery and radiotherapy for the treatment of malignant glioma. Cancer Treat Rep 1983; 67:121-32.

6 Andreaon J, George AE, Wise A, et al. CT prognostic criteria of survival after malignant glioma surgery. $\mathrm{Am} \mathrm{J}$ Neuroradiol 1983;4:488-90.

7 Ammirati J, Vick N, Liao J, Ciric I, Mikhael M. Effect of the extent of surgical resection on survival and quality of life in patients with supratentorial glioblastomas and anaplastic patients with supratentorial glioblastomas and
astrocytomas. Neurosurgery 1987;21:201-6.

8 Ciric I, Ammirati M, Vick N, Mikhael M. Supratentorial gliomas: surgical considerations and immediate post-

9 Fadul C, Wood J, Thaler H, Galicich J, Patterson RH, Posner JB. Morbidity and mortalilty of craniotomy for excision of supratentorial gliomas. Neurology 1988;38: 1374-9.

10 Wroe SJ, Foy PM, Shaw MDM, et al. Differences between neurological and neurosurgical approaches in the management of malignant brain tumours. Br Med J 1986; 293:1015-8.

11 Todd NV, McDonagh T, Miller JD. What follows diagnosis by computed tomography of solitary brain tumour? Lancet 1987;ii:611-2.

12 Borgelt B, Gelber RD, Kramer S, et al. The palliation of brain metastases: final results of the first two studies by the brain metastases: final results of the first two studies by the
Radiation Therapy Oncology Group. Int J Radiat Oncol
Biol Phys 1980;6:1-9.

13 McComb RD, Burger PC. Pathologic analysis of brain tumors. Neurologic Clinics 1985;3:711-28.

14 Nelson JS, Tsukada J, Schoenfeld D, Fulling K, Lamarche $\mathrm{J}$. Necrosis as a prognostic criterion in malignant supratentorial, astrocytic gliomas. Cancer 1983;52:550-4.

15 Nelson DF, Nelson JS, Davis DR, Chang CH, Griffin TW, Pajak TF. Survival and prognosis of patients with astrocytoma with atypical or anaplastic features. J NeuroOncol 1985;3:99-103.

16 Frankel SA, German WJ. Glioblastoma multiforme. Review of 219 cases with regard to natural history, diagnostic methods and treatment. J Neurosurg 1958;15:489-503.

17 Jelsma R, Bucy PC. The treatment of glioblastoma multiforme of the brain. J Neurosurg 1967;27:388-400.

18 Gleave JRW. Surgery for primary brain tumours. In: Bleehan NM, ed. Tumours of the brain. Berlin: Springer Bleehan NM, ed. T
Verlag 1986:101-20.

19 Punt J. Does biopsy or any surgery influence the outcome in patients with supratentorial malignant gliomas? In: Warlow CP, Garfield JS, eds. Dilemmas in the management of the neurological patient. Edinburgh: Churchill Livingstone, vol 1:158-67.

20 Tandon PN, Agarcoal SP, Mahapatra AK, Roy S. Radical surgical decompression of supratentorial gliomas. Do the results justify the operation? In: Walker $M$, Thomas DGT, eds. Biology of brain tumour. Boston: Martinus Nijhoff 1986:277-86.

21 Roth JC, Elvidge AR. Glioblastoma multiforme: a clinical survey. J Neurosurg 1960;17:736-50.

22 Weir $B$. The relative significance of factors affecting postoperative survival in astrocytomas, grade 3 and 4 . J Neurosurg 1973;38:448-52.

23 Yamashita T, Kuwabara T. Estimation of growth of malig nant brain tumors by computed tomography scanning. nant brain tumors by compute
Surg Neurol 1983;20:464-70.

24 Laws ER, Taylor WF, Clifton MB, Okazaki H. Neurosurgical management of low-grade astrocytoma of the cerebral hemispheres. J Neurosurg 1984;61:665-73. 